\title{
Perbandingan Algoritma Simulated Annealing dan Harmony Search dalam Penerapan Picking Order Sequence
}

\author{
Tanti Octavia $^{1^{*}}$, Septianda Angelica ${ }^{1}$
}

\begin{abstract}
Implementation of mobile rack warehouse is commonly used in manufacturing industry because it can minimize the warehouse area used. Applying picking orders in taking of Stock Keeping Unit (SKU) on mobile rack warehouses could give fast loading order. This research aims to find out which algorithm is better in applying picking order sequence in mobile rack warehouse. The algorithms used are Simulated Annealing (SA) and Harmony Search (HS) algorithm. Both of these algorithms will be compared in terms of the gap with the shortest path method and CPU time. The result shows that the HS algorithm produces a better solution than the SA algorithm with lower CPU time, but the convergence rate of HS is lower than that of SA.HS was able to produce a better solution than the shortest path method of nine cases, while SA only eight cases from fifteen cases.
\end{abstract}

Keywords: Picking order sequence, simulated annealing, harmony search.

\section{Pendahuluan}

Penyimpanan memiliki peranan penting dalam industri manufaktur. Gudang sangat dibutuhkan dalam proses penyimpanan agar barang yang disimpan tidak rusak dan tetap terjaga. Pengaturan gudang yang optimal juga dapat meminimalkan penggunaan tempat sehingga dapat meningkatkan kapasitas gudang yang ada. Adapun pengaturan gudang dapat dilakukan seperti mengatur peletakan barang yang disimpan, mengubah tata letak gudang yang ada, serta penggunaan media penyimpanan seperti rak.

Penggunaan mobile rack warehouse umumnya cocok digunakan karena dapat menghemat tempat yang tersedia dan dapat bergerak secara otomatis. Dimana, pengambilan stock keeping unit (SKU) yang terletak pada rak dilakukan oleh storage and retrieval vehicle (SRV). Kecepatan dan waktu yang dibutuhkan untuk mengambil SKU sesuai yang diperlukan akan sangat tergantung pada penataan serta relokasi rak yang optimal agar waktu tempuh SRV dalam mengambil SKU semakin optimal.

Penataan serta urutan pengambilan (picking order sequence) SKU dengan lokasi yang berdekatan akan mengoptimalkan waktu pengambilan SKU. Dimana pada penelitian ini akan dilakukan optimalisasi kecepatan dan waktu pengambilan SKU dengan menggunakan metode algorithma simulated annealing (SA) and harmony search (HS).

\footnotetext{
${ }^{1}$ Fakultas Teknologi Industri, Program Studi Teknik Industri, Universitas Kristen Petra, Jl. Siwalankerto 121-131, Surabaya 60238, Indonesia.

Email:tanti@petra.ac.id

* Penulis korespondensi
}

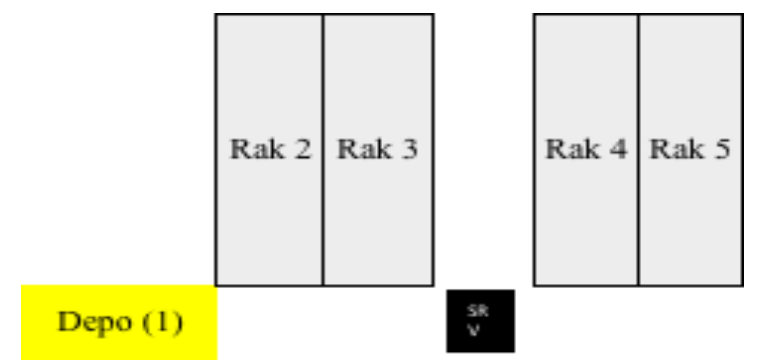

Gambar 1. Gambaran permasalahan

\begin{tabular}{|c|c|}
\hline Rak 2 & Rak 3 \\
\hline 3 & 6 \\
\hline 2 & 5 \\
\hline 1 & 4 \\
\hline
\end{tabular}

\begin{tabular}{|c|c|}
\hline Rak 4 & Rak 5 \\
\hline 9 & 12 \\
\hline 8 & 11 \\
\hline 7 & 10 \\
\hline
\end{tabular}

Depo (1)

Gambar 2. Contoh penempatan SKU

Seperti contohnya sebuah gudang memiliki empat buah rak dan satu depo (Gambar 1). Picking order yang diberikan berupa nomor SKU yang memiliki demand tertentu dan selanjutnya dikelompokkan ke masing-masing rak.

Setiap SKU ditempatkan pada suatu rak saja dan tidak berpindah-pindah. Peletakan SKU pada setiap rak dilakukan secara berurutan, dimana nomor SKU terkecil akan terletak pada nomor rak terkecil (Gambar 2).

Pengambilan order yang pertama kali berdasarkan dari rak yang terbuka pertama kali. Rak yang terbuka pertama kali didapatkan dari membangkitkan bilangan acak. Pengambilan order membutuhkan 
alokasi rak untuk membuka aisle dimana setiap rak hanya memiliki satu aisle saja. Pertama kali SRV akan berada di depo, kemudian SRV akan bergerak mengambil order ke masing-masing rak.

Pengaksesan SKU membutuhkan pergerakan rak selama empat meter/menit. SRV akan memiliki kapasitas tertentu, dimana pada penelitian iniSRV memiliki kapasitas 100.

\section{Metode Penelitian}

\section{Pengembangan Model}

Model yang akan dikembangkan pada penelitian ini terdiri dari: (1) model awal dengan algoritma simulated annealing (SA) dan harmony search (HS); (2) model dengan shortest path (SP). Model awal dikembangkan dengan cara membangkitkan rute pengambilan SKU secara random, sedangkan model shortest path dikembangkan dengan cara mencari rute dengan waktu tempuh terpendek. Metode ini akan digunakan sebagai pembanding untuk algoritma SA dan HS karena metode shortest path cukup mampu menghasilkan solusi paling minimum meskipun membutuhkan waktu yang cukup lama.

Batasan pada penelitian ini adalah hanya menggunakan satu buah SRV dan SRV tidak diperbolehkan mengalami backtracking. Batasan ini ditujukan agar dapat meminimalkan waktu tempuh dari SRV. Adapun total waktu tempuh optimal dilihat pada persamaan berikut ini:

$\operatorname{Min} F(x)=\sum_{i=2}^{n} \sum_{j=1}^{m} \sum_{k=2}^{n} \sum_{l=1}^{m} W_{i k} X_{i j} X_{k l}$

dengan kendala:

$\sum_{i=2}^{n} d i \times \sum_{j=1}^{m} \sum_{k=2}^{n} \sum_{l=1}^{m} X_{k l} X_{i j}$

$\sum_{j=1}^{m} X_{i j}=1, \quad i=2,3,4,5 \ldots n$

$\sum_{i=2}^{n} X_{i j}=1, j=2,3,4,5 \ldots n$

dimana:

$W_{i k}=$ Waktu tempuh $\operatorname{rak} i$ ke rak $k$

$X_{i j}=\left\{\begin{array}{l}1 \\ 0\end{array}\right.$

$X_{i j}=$ integer

$i \neq k, j \neq l$

Persamaan (2) digunakan untuk membatasi total permintaan yang dibawa oleh SRV tidak melebihi kapasitas. Persamaan (3) dan (4) menunjukkan bahwa semua kemungkinan peletakan rak $i$ pada rute $j$ akan dilakukan sesuai dengan jumlah rak $(n)$ dan rute $(m)$ dan rak $i$ hanya berada pada satu rute $j$. Jumlah rak dimulai dari angka 2 karena angka 1 menunjukkan depo dimana depo tidak boleh dikunjungi apabila kapasitas SRV masih ada. $X_{i j}$ bernilai 1 jika rak $i$ berada pada rute $j$ dan akan bernilai 0 jika berlaku sebaliknya. Contoh terdapat sebuah rute yaitu $(2,3) . X_{i j}$ pada rute ini adalah $X_{21}$ yang berarti rak 2 berada di rute $1 . X_{k l}$ pada rute ini adalah $X_{32}$ yang berarti rak 3 berada di rute $2 . W_{k l}$ pada rute ini adalah $W_{23}$ yang berarti waktu tempuh dari rak 2 ke rak 3.

\section{Model Shortest Path}

Metode ini akan mencari rute dengan waktu tempuh terpendek dengan membandingkan rute mana yang memiliki waktu tempuh paling pendek.

Contohnya pada Gambar 3 rak nomor 2 akan diperiksa ke seluruh rute untuk mengetahui rute manakah yang memiliki waktu tempuh terpendek. Dari hasil pencarian, rak nomor 2 memilih rute menuju rak nomor 3 karena rute tersebut memiliki waktu tempuh terpendek. Langkah ini kemudian diulang hingga semua permintaan terpenuhi.

\section{Algoritma Simulated Annealing (SA)}

Simulated Annealing (SA) merupakan algoritma yang digunakan untuk mencari nilai optimal dengan mengontrol nilai dari temperatur (Atmaca dan Ozturk [1]). SA memiliki beberapa parameter yaitu temperatur awal, jumlah penurunan temperatur, derajat penurunan, dan jumlah replikasi setiap temperatur.

Adapun penetapan parameter pada penelitian ini mengacu pada Suman dan Kumar [2], Bosyen et al [3], dan Yang [4]. Temperatur awal didapatkan dari persamaan berikut ini [4]:

$$
T_{0}=\frac{-\max \Delta f}{\ln P o}
$$

Nilai $\Delta f$ didapatkan dari pengurangan antara solusi baru dan lama, dimana solusi baru didapatkan dari pengembangan solusi awal dengan menukar dua rute secara random. Misalnya pada solusi awal, hasil yang diperoleh adalah $(2,3,4,5)$, pada solusi baru diperoleh $(2,4,3,5)$. Maka hasil waktu tempuh solusi baru akan dikurangkan dengan hasil waktu tempuh dari solusi lama.

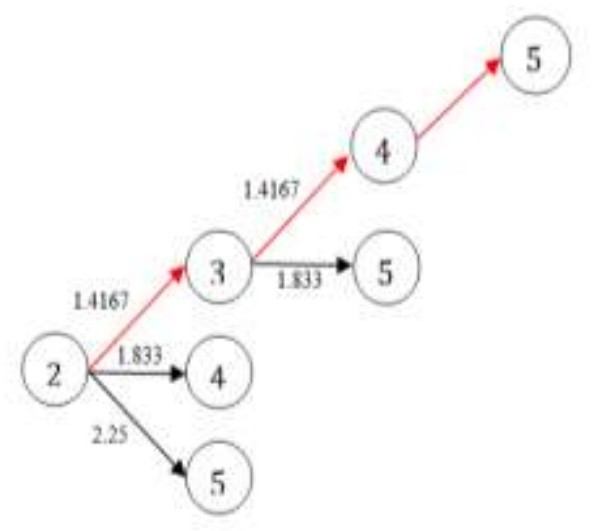

Gambar 3. Contoh penerapan metode shortest path 


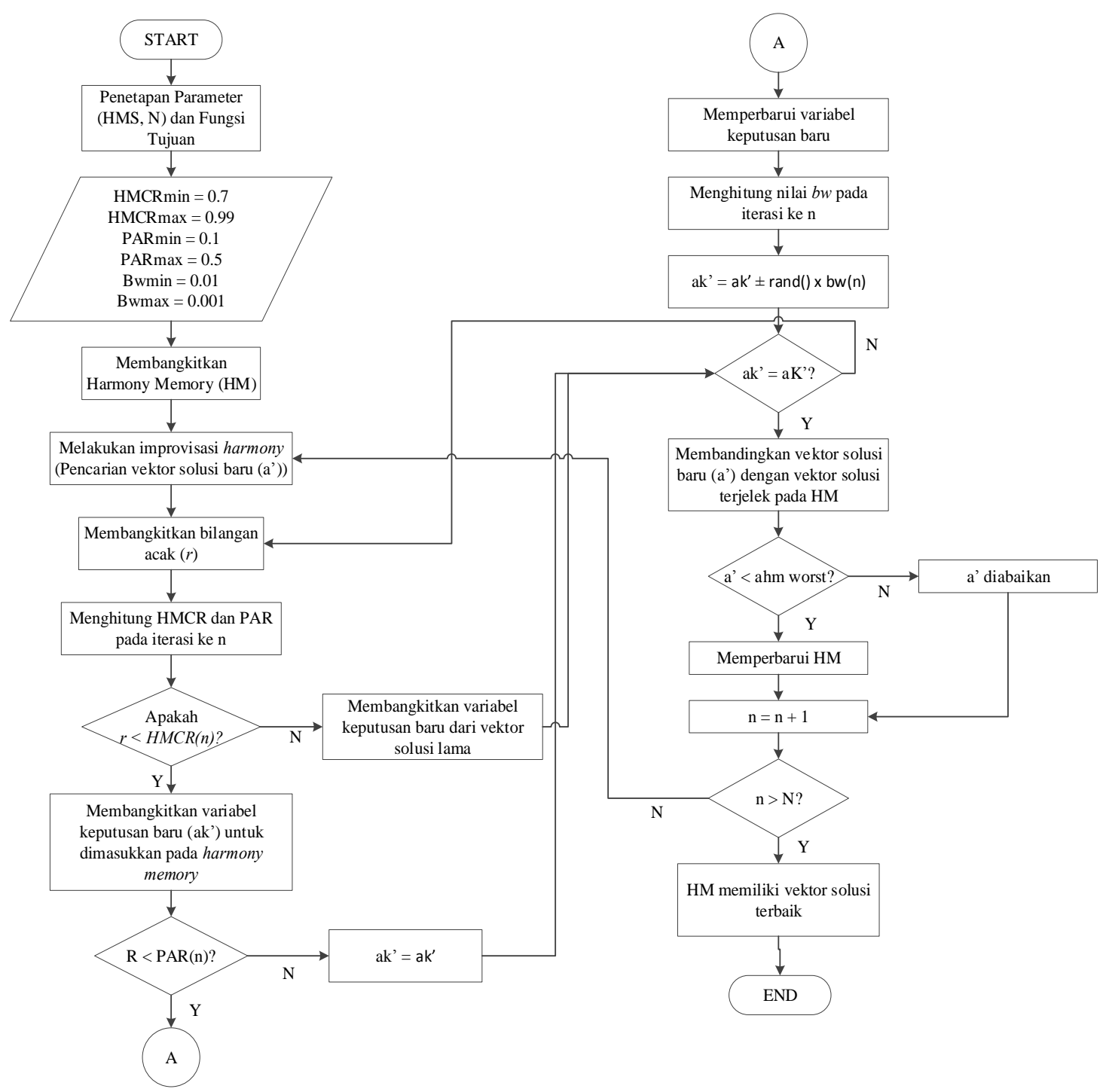

Gambar 4. Flowchart algoritma harmony search

SA akan membangkitkan solusi baru dengan dua metode yaitu swap two dan push away. Metode ini sebelumnya sudah dikembangkan oleh Bosyen et al. [3]. Pada penelitian ini ditentukan metode swap two yang terjadi sebanyak $90 \%$ dan push away sebesar $10 \%$. Contoh dari metode swap two adalah sebagai berikut. Ketika didapatkan solusi awal yaitu (2,4,$3,5)$ maka metode swap two akan menukar dua rute secara acak, sehingga solusi baru menjadi $(2,3,5,4)$.

Contoh penggunaan dari metode push away adalah pada saat solusi awal didapatkan $(2,3,5,4)$. Metode push away akan meletakkan salah satu rak ke rute paling terakhir sehingga solusi baru menjadi $(2,5,4,3)$. Penentuan rak mana yang akan dipilih berdasarkan hasil random data.

Nilai dari Po menurut Suman dan Kumar [2] memiliki kisaran antara $0,5-0,95$, sedangkan untuk penelitian nilai Po yang digunakan sebesar
0,95. Parameter selanjutnya yaitu derajat penurunan sebesar 0,995 (Bosyen et al. [3]), jumlah penurunan temperatur sebanyak $1000 \mathrm{kali}$, dan jumlah replikasi setiap temperatur sebanyak 5 kali.

\section{Algoritma Harmony Search (HS)}

Harmony search (HS) adalah algoritma yang digunakan untuk mencari nilai optimal yang terinspirasi dari musisi yang mengimprovisasi pitch instrument untuk mendapatkan harmoni yang baik (Zong [5]). Beberapa penelitian dan pengembangan algoritma HS telah dilakukan baik dalam perbaikan parameter algoritma HS itu sendiri maupun perbaikan penerapan algoritma HS dengan algoritma metaheuristik lain (Alia dan Mandava [6]), misalnya: Ant colony (Yun et al. [7]). Penerapan algoritma HS ini telah banyak dilakukan pada permasalahan traveling salesman problem (Yun et al.[7], Zong et al. [8]); joshop problem (Aulia [9]); maupun four colour mapping (Daham et al. [10]). Penerapan algoritma 
HS pada ketiga permasalahan di atas telah memberikan hasil yang lebih baik.

Beberapa parameter yang dimiliki HS yaitu harmony memory (HM), harmony memory consideration rate (HMCR), harmony memory size (HMS), pitch adjusting rate (PAR), dan jumlah iterasi $(\mathrm{N})$. Penetapan parameter pada penelitian ini berdasarkan dari Yang [4], Zong [5], dan Daham et al. [10].

$$
\mathrm{HM}=\left[\begin{array}{cccc|c}
a_{1}^{1} & a_{2}^{1} & \ldots & a_{N}^{1} & f\left(a^{1}\right) \\
a_{1}^{2} & a_{2}^{2} & \ldots & a_{N}^{2} & f\left(a^{2}\right) \\
\vdots & \vdots & \ldots & \vdots & \vdots \\
a_{1}^{\mathrm{HMS}} & a_{2}^{\mathrm{HMS}} & \cdots & a_{N}^{\mathrm{HMS}} & f\left(a^{\mathrm{HMS}}\right)
\end{array}\right]
$$

HM berisi vektor-vektor solusi sebanyak HMS, dimana vektor-vektor solusi pada penelitian ini didapatkan secara random. Parameter selanjutnya yaitu HMS sebesar 40, jumlah iterasi sebanyak 1000. Parameter HMCR dan PAR tidak ditetapkan secara pasti tetapi didapatkan melalui persamaan (7):

$$
\begin{aligned}
& \left.\operatorname{HMCR}(\min )=\left(\frac{\text { HMCRmax }-H M C R \min }{N}\right) \times n\right) \\
& \left.\operatorname{PAR}(\min )=\left(\frac{\text { PARmax }- \text { PARmin }}{N}\right) \times n\right)
\end{aligned}
$$

Gambar 4 menunjukkan bagaimana algoritma HS dijalankan. HS akan membangkitkan vektor solusi baru berdasarkan dari vektor solusi yang berada di HMS.

\section{Hasil dan Pembahasan}

Simulasi dilakukan dengan menggunakan visual basic application pada aplikasi Microsoft Excel. Simulasi dijalankan menggunakan Laptop dengan spesifikasi prosesor Intel Gen-7 Core i7-7700HQ dan memori DDR416 GB 2400Mhz. Simulasi dilakukan pada kasus permasalahan dengan jumlah rak $(10,20,30,40,50)$ dan jumlah order $(25,50,100)$. Setiap kasus direplikasi sebanyak 50 kali.

Simulasi dilakukan pada kedua metode dengan mengganti parameter pada model sebanyak tiga kali. Pergantian parameter dilakukan untuk mengetahui pengaruh perubahan parameter terhadap hasil dari fungsi tujuan dan CPU time simulasi tersebut.

\section{Parameter Pertama}

Parameter ini adalah parameter awal untuk kedua algoritma. Parameter pertama SA adalah sebagai berikut:

\section{Temperatur awal}

Temperatur awal didapatkan dari persamaan (5). Perhitungan nilai $\Delta f$ dilakukan untuk mengetahui nilai maksimum $\Delta f$ dari permasalahan (lihat Tabel
Tabel 1. Nilai $\Delta f$ setiap kasus

\begin{tabular}{cccc}
\hline Rak/order & 25 & 50 & 100 \\
\hline 10 & $-7,6933$ & $-11,861$ & $-11,515$ \\
20 & $-34,186$ & $-23,627$ & $-43,358$ \\
30 & $-22,559$ & $-34,921$ & $-36,697$ \\
40 & $-39,922$ & $-31,953$ & $-79,021$ \\
50 & $-52,790$ & $-62,564$ & $-83,220$ \\
\hline
\end{tabular}

Tabel 2. Rata-rata selisih waktu terpendek algoritma SA dan HS dengan shortest path (SP) parameter pertama

\begin{tabular}{crrr}
\hline Jumlah rak & Jumlah order & SA-SP & HS-SP \\
\hline \multirow{2}{*}{10} & 25 & $-6,8986$ & $-13,535$ \\
& 50 & 17,069 & 0 \\
\multirow{4}{*}{20} & 100 & 18,211 & $-2,0783$ \\
& 25 & 47,791 & 18,795 \\
& 50 & 44,749 & 39,924 \\
30 & 100 & $-3,3398$ & $-7,4702$ \\
& 25 & $-17,338$ & $-35,935$ \\
40 & 50 & 36,762 & 12,815 \\
& 100 & 36,461 & $-49,384$ \\
& 25 & 84,147 & 18,795 \\
50 & 50 & $-37,187$ & $-37,237$ \\
& 100 & $-8,8917$ & $-26,021$ \\
& 25 & $-10,444$ & $-30,821$ \\
& 50 & 77,167 & 6,0613 \\
& 100 & 0 & 0 \\
\hline
\end{tabular}

1). Nilai yang diambil adalah $-7,6933$ yaitu pada kasus jumlah rak 10 dengan jumlah order 25 . Nilai ini akan digunakan pada perhitungan temperatur awal dengan Po sebesar 0,95. Temperatur awal yang didapatkan sebesar 149,99.

Parameter HS yang pertama adalah sebagai berikut:

Harmony Memory Size : 40

HMCR dan PAR didapatkan melalui persamaan (6) dan (7) yang dihitung pada setiap iterasi (n)

Jumlah iterasi $(\mathrm{N}) \quad: 1000$

Jumlah penurunan $\quad: 1000$

Derajat penurunan $\quad: 0,995$

Replikasi setiap temperatur: 5

Tabel 2 menunjukkan hasil antara kedua algoritma (SA dan HS) dengan metode shortest path. Hasil simulasi menunjukkan bahwa HS mampu mendapatkan hasil yang lebih baik daripada SA. Hal itu ditunjukkan dari 15 kasus yang dikembangkan, HS mampu lebih baik dari metode shortest path sebanyak 8 kasus. SA hanya mampu memiliki hasil yang lebih baik dari metode shortest path sebanyak 6 kasus.

Gambar 5 dan 6 menunjukkan bahwa algoritma SA lebih mampu menghasilkan hasil yang lebih konvergen dibandingkan algoritma HS. Hal ini dapat dilihat bahwa SA mulai menghasilkan solusi yang konvergen saat memasuki temperatur kelima atau memasuki iterasi ke 600. HS baru mulai menghasilkan solusi yang konvergen saat memasuki iterasi ke 900. Hal ini berarti SA mampu menghasilkan solusi dengan variasi yang lebih kecil dibandingkan HS. 
Tabel 3 menunjukkan waktu pengerjaan masingmasing algoritma dalam satuan menit. SA memiliki rata-rata waktu pengerjaan selama 180,7826 menit, sedangkan HS selama 81,1056 menit. Hasil ratarata ini menunjukkan bahwa HS dapat menghasilkan solusi yang lebih cepat dibandingkan SA.

\section{Parameter Kedua}

Parameter ini ditentukan dengan mengurangi jumlah iterasi untuk masing-masing algoritma. Parameter kedua algoritma SA adalah sebagai berikut :

Temperatur awal

Jumlah penurunan

: 149,99

Derajat penurunan

$: 500$

$: 0,995$

Replikasi setiap temperatur: 5

Perubahan temperatur SA ini berdasarkan dari hasil konvergensi yang menunjukkan bahwa SA sudah mampu menghasilkan solusi yang konvergen pada saat memasuki iterasi ke 600. Parameter HS yang kedua adalah sebagai berikut:

Harmony memory size: 40

HMCR dan PAR didapatkan melalui persamaan (6) dan (7) yang dihitung setiap iterasi (n)

Jumlah iterasi (N): 500

HS masih mendapatkan hasil yang lebih baik daripada SA. Hal itu ditunjukkan dari 15 kasus, HS memiliki hasil yang lebih baik dari metode shortest path sebanyak 9 kasus, sedangkan SA sebanyak 5 kasus.

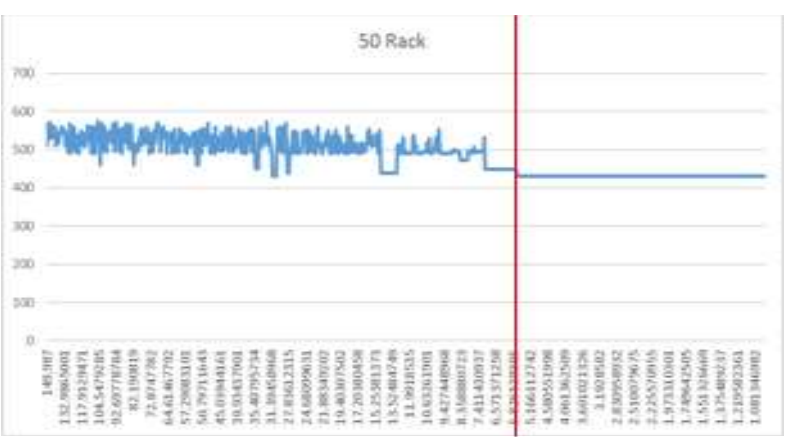

Gambar 5. Konvergensi simulated annealing

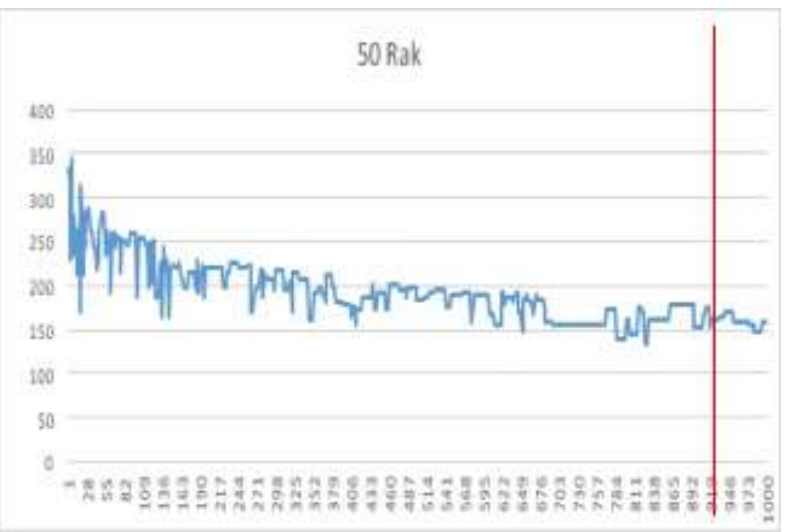

Gambar 6. Konvergensi harmony search
Tabel 3. Hasil CPU time parameter pertama (dalam menit)

\begin{tabular}{|c|c|c|c|}
\hline Jumlah rak & Jumlah order & $\mathrm{SA}$ & $\mathrm{HS}$ \\
\hline \multirow[t]{3}{*}{10} & 25 & 110,1 & 37,433 \\
\hline & 50 & 131,4 & 36,117 \\
\hline & 100 & 134,783 & $42,88 ?$ \\
\hline \multirow[t]{3}{*}{20} & 25 & 145,25 & 36,117 \\
\hline & 50 & 173,983 & 34,6 \\
\hline & 100 & 181,917 & 30, \\
\hline \multirow[t]{3}{*}{30} & 25 & 142 & 31, \\
\hline & 50 & 181,05 & 133,733 \\
\hline & 100 & 221,067 & 134,167 \\
\hline \multirow[t]{3}{*}{40} & 25 & 147,983 & 41,8 \\
\hline & 50 & 215,983 & 54 \\
\hline & 100 & 248,04 & 144,05 \\
\hline \multirow[t]{3}{*}{50} & 25 & 214,083 & 125,367 \\
\hline & 50 & 213,683 & 175,867 \\
\hline & 100 & 250,417 & 157,6 \\
\hline Rat & ta-rata & 180,7826 & 81,1056 \\
\hline
\end{tabular}

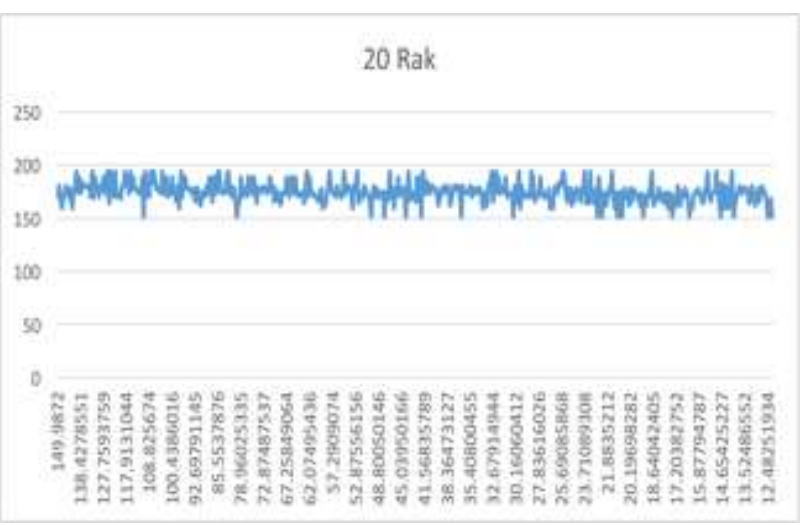

Gambar 7. Konvergensi simulated annealing

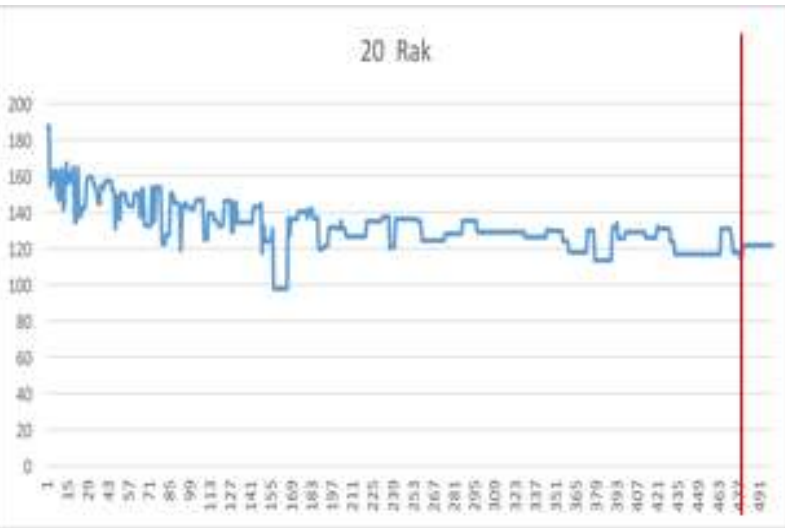

Gambar 8. Konvergensi harmony search

Hasil pergantian parameter menunjukkan bahwa hasilkan solusi yang lebih konvergen daripada parameter pertama. Hal itu dikarenakan jumlah iterasi yang semakin sedikit menunjukkan bahwa jumlah tersebut masih belum cukup untuk mendapatkan hasil yang konvergen. Parameter kedua ini HS lebih baik dalam menghasilkan solusi yang lebih konveren, walaupun HS menghasilkan solusi yang konvergen pada saat memasuki iterasi ke 470 . 
Tabel 4. Rata-rata selisih waktu terpendek algoritma SA dan HS dengan shortest path (SP) parameter kedua

\begin{tabular}{crrr}
\hline Jumlah rak & Jumlah order & \multicolumn{1}{c}{ SA-SP } & \multicolumn{1}{c}{ HS-SP } \\
\hline \multirow{2}{*}{10} & 25 & $-5,533536$ & $-11,49738$ \\
& 50 & $-12,42853$ & $-10,4164$ \\
20 & 100 & $-44,4382$ & $-29,0162$ \\
& 25 & 15,076138 & 6,68741 \\
& 50 & 45,133386 & $-44,461196$ \\
30 & 100 & 19,273 & $-27,4406$ \\
& 25 & $-42,02161$ & $-31,48758$ \\
& 50 & 71,38797 & $-25,184357$ \\
40 & 100 & 14,1265 & $-21,4100053$ \\
& 25 & 56,7382 & 27,98565 \\
& 50 & 83,5331 & 11,201 \\
50 & 100 & 79,289318 & 28,1444 \\
& 25 & 37,374504 & $-21,32427$ \\
& 50 & $-15,01927$ & 86,234 \\
& 100 & 2,140286 & 104,289925 \\
\hline
\end{tabular}

Tabel 5. Hasil CPU time parameter kedua (dalam menit)

\begin{tabular}{|c|c|c|c|}
\hline Jumlah rak & Jumlah order & SA & $\mathrm{HS}$ \\
\hline \multirow[t]{3}{*}{10} & 25 & 56,133 & 22,7 \\
\hline & 50 & 57,6167 & 32,133 \\
\hline & 100 & 79 & 38,6333 \\
\hline \multirow[t]{3}{*}{20} & 25 & 70,433 & 18,783 \\
\hline & 50 & 72,4 & 19,9167 \\
\hline & 100 & 94,033 & 20,45 \\
\hline \multirow[t]{3}{*}{30} & 25 & 86,3833 & 21,2833 \\
\hline & 50 & 95,8 & 25,733 \\
\hline & 100 & 111,8 & 20,9667 \\
\hline \multirow[t]{3}{*}{40} & 25 & 95,433 & 34,3667 \\
\hline & 50 & 100,433 & 27,6667 \\
\hline & 100 & 130,417 & 38,5 \\
\hline \multirow[t]{3}{*}{50} & 25 & 106,75 & 35,9333 \\
\hline & 50 & 111,217 & 29,5333 \\
\hline & 100 & 155,717 & 41,2667 \\
\hline \multicolumn{2}{|c|}{ Rata-rata } & 94,9044 & 28,52438 \\
\hline
\end{tabular}

Tabel 6. Rata-rata selisih waktu terpendek algoritma SA dan HS dengan shortest path (SP) parameter ketiga

\begin{tabular}{crrr}
\hline Jumlah rak & Jumlah order & \multicolumn{1}{c}{ SA-SP } & \multicolumn{1}{c}{ HS-SP } \\
\hline 10 & 25 & $-6,2877$ & $-11,49738$ \\
& 50 & $-5,9812$ & $-10,4164$ \\
& 100 & $-26,613$ & $-29,0162$ \\
20 & 25 & 19,8819 & 6,68741 \\
& 50 & 42,3377 & $-44,461196$ \\
& 100 & $-45,152$ & $-27,4406$ \\
30 & 25 & 12,5476 & $-31,48758$ \\
& 50 & 34,4871 & $-25,184357$ \\
& 100 & $-34,091$ & $-21,4100053$ \\
40 & 25 & -15 & 27,98565 \\
& 50 & 68,8062 & 11,201 \\
50 & 100 & 8,68817 & 28,1444 \\
& 25 & $-11,008$ & $-21,32427$ \\
& 50 & 22,3898 & 86,234 \\
& 100 & $-24,371$ & 104,289925 \\
\hline
\end{tabular}

Tabel 5. menunjukkan SA memiliki rata-rata waktu pengerjaan selama 94,9044 menit, sedangkan HS selama 28,52438 menit. Hasil rata-rata ini menunjukkan bahwa HS masih lebih cepat dalam segi waktu pengerjaan debandingkan SA.

\section{Parameter Ketiga}

Parameter ini ditentukan dengan mengganti derajat penurunan dari algoritma SA. Parameter kedua algoritma SA adalah sebagai berikut :

Temperatur awal $\quad: 149,99$

Jumlah penurunan $\quad: 500$

Derajat penurunan $\quad: 0,8$

Replikasi setiap temperatur: 5

Pergantian derajat penurunan dilakukan untuk mengetahui penaruh derajat penurunan terhadap hasil yang didapatkan. Parameter HS yang kedua adalah sebagai berikut:

Harmony Memory Size: 40

HMCR dan PAR didapatkan melalui persamaan (6) dan (7) yang dihitung setiap iterasi (n)

Jumlah iterasi (N): 500

Hasil pergantian parameter ketiga menunjukkan bahwa HS masih mendapatkan hasil yang lebih baik daripada SA. Hal itu ditunjukkan dari 15 kasus, HS memiliki hasil yang lebih baik dari metode shortest path sebanyak 9 kasus, sedangkan SA sebanyak 8 kasus.

SA menghasilkan solusi yang paling baik pada saat parameter ketiga karena menghasilkan solusi yang lebih baik daripada metode shortest path paling banyak dibandingkan parameter lainnya.

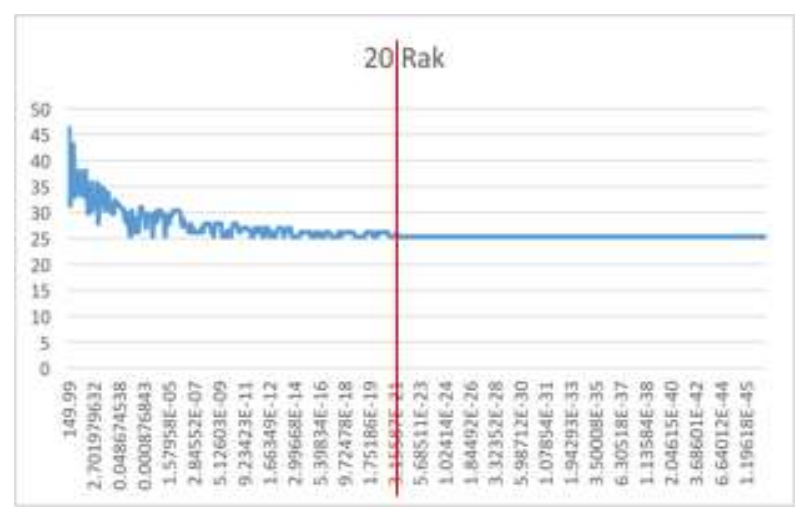

Gambar 9. Konvergensi simulated annealing

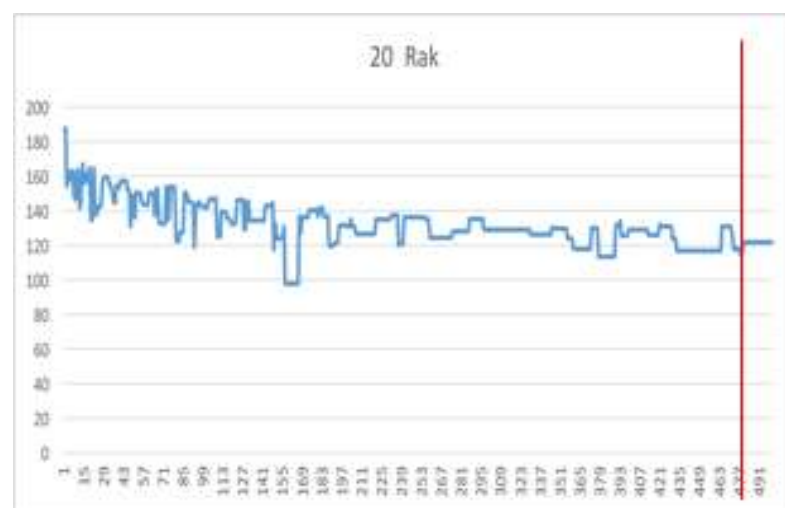

Gambar 10. Konvergensi harmony search 
Tabel 7. Hasil CPU time parameter ketiga (dalam menit)

\begin{tabular}{crrr}
\hline Jumlah rak & Jumlah order & \multicolumn{1}{c}{ SA } & \multicolumn{1}{c}{ HS } \\
\hline \multirow{2}{*}{10} & 25 & 63,8167 & 22,7 \\
& 50 & 69,15 & 32,133 \\
& 100 & 70,2167 & 38,6333 \\
20 & 25 & 63,8 & 18,783 \\
& 50 & 67,0667 & 19,9167 \\
& 100 & 72,95 & 20,45 \\
30 & 25 & 63,4 & 21,2833 \\
& 50 & 94,9667 & 25,733 \\
& 100 & 105,8 & 20,9667 \\
40 & 25 & 63,1667 & 34,3667 \\
& 50 & 112,5 & 27,6667 \\
& 100 & 127,4 & 38,5 \\
50 & 25 & 95,6833 & 35,9333 \\
& 50 & 19,283 & 29,5333 \\
& 100 & 165 & 41,2667 \\
\hline \multicolumn{2}{c}{ Rata - rata } & 83,61332 & 28,52438 \\
\hline
\end{tabular}

Gambar 9 dan 10 menunjukkan bahwa SA pada parameter ketiga mampu menghasilkan solusi yang paling konvergen diantara parameter-parameter sebelumnya. Hal itu ditunjukkan pada saat iterasi ke 235 atau pada saat temperatur 3.15E-21 SA sudah menghasilkan solusi yang konvergen. SA mampu menghasilkan solusi yang lebih konvergen dibandingkan HS. Hal ini berarti SA parameter ketiga mampu menghasilkan solusi dengan varians yang kecil.

Tabel 7 menunjukkan SA memiliki rata-rata waktu pengerjaan selama 83,61332 menit, sedangkan HS selama 28,52438 menit. Hasil rata-rata ini menunjukkan bahwa HS membutuhkan waktu yang lebih cepat dalam memberikan hasil dibandingkan SA.

\section{Simpulan}

Hasil penelitian menunjukkan algoritma simulated annealing memberikan rata-rata waktu tempuh yang lebih singkat dibandingkan metode shortest path dengan rata-rata CPU time sebesar 180,78 menit untuk 8 dari 15 permasalahan. Hasil simulasi juga menunjukkan algoritma harmony search memberikan rata-rata waktu tempuh yang lebih pendek pada 9 dari 15 permasalahan dibandingkan metode shortest path dengan rata-rata CPU time sebesar 81,106 menit.
Algoritma harmony search menghasilkan solusi yang paling baik ketika jumlah iterasi 500 dan 40 . Hasil penelitian juga menunjukkan algoritma harmony search memberikan solusi yang lebih baik dibandingkan algoritma simulated annealing dengan CPU time yang lebih rendah, akan tetapi, algoritma simulated annealing mampu menghasilkan solusi yang lebih konvergen dibandingkan harmony search.

\section{Daftar Pustaka}

1. Atmaca, E., Ozturk, A., Defining Order Picking Policy: A Storage Assignment Model and a Simulated Annealing Solution in AS/RS Systems, Applied Mathematical Modelling, 37, 2012, pp. 5069-5079.

2. Suman, B., and Kumar, P., A Survey of Simulated Annealing as a Tool for Single and Multiobjective Optimization, Journal of the Operational Research Society, 57, 2006, pp.11431160.

3. Boysen, N., Briskorn, D., and Emde, S., Sequencing of Picking Orders in Mobile Rack Warehouse, European Journal of Operational Research, 259(2017), 2016, pp. 293-307.

4. Yang, X. S., Nature-Inspired Metaheuristic Algorithms, United Kingdom: Luniver Press, 2010.

5. Zong, W. G., Music Inspired Harmony Search Algorithm Theory and Applications, New York: Springer, 2009.

6. Alia, O. M., Mandava, R., The Variants of the Harmony Search Algorithm: An Overview, Springer Science Business Media B.V., 2011.

7. Yun, H. Y., Jeong, S. J., Kim, K. S., Advanced Harmony Search with Ant Colony Optimization for Solving the Traveling Salesman Problem, Journal of Applied Mathemetics, 2013, pp. 29-37.

8. Zong, W. G., Kim, J. H., Loganathan, G. V., A New Heuristic Optimization Algorithm: Harmony Search, Simulation Council, 75, 2001, pp. 60-68.

9. Aulia, I., Nababan, E. B., dan Muchtar, M. A. Penerapan Harmony Search Algorithm dalam Permasalahan Penjadwalan Flow Shop, Jurnal Dunia Teknologi Informasi, 1(1), 2012, pp. 1-7.

10. Daham, B. F., Mohammed, N. M., and Mohammed, S. K., Modified Harmony Search Alogrithm for Solving the Four-Color Mapping Problem, International Journal of Computer Application, 91(6), 2014, pp. 975-8887. 